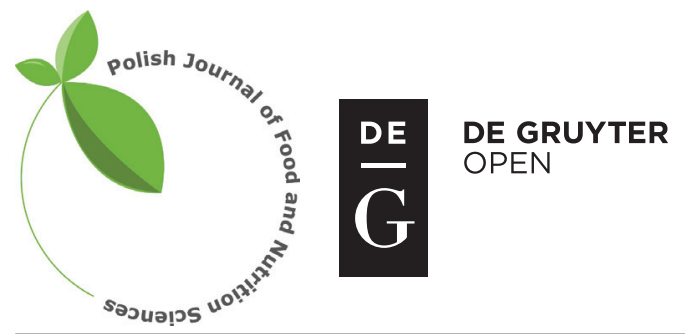

Pol. J. Food Nutr. Sci., 2016, Vol. 66, No. 3, pp. 173-178

DOI: $10.1515 /$ pjfns-2015-0032 http://journal.pan.olsztyn.pl

Original article

Section: Food Quality and Functionality

\title{
Total Oil Content and Fatty Acid Profile of Some Almond (Amygdalus communis L.) Cultivars
}

\author{
Adnan Nurhan Yildirim ${ }^{1 *}$, Fatma Akinci-Yildirim ${ }^{1}$, Bekir Şan ${ }^{1}$, Yllmaz Sesli $^{2}$ \\ ${ }^{1}$ Department of Horticulture, Agriculture Faculty, Suleyman Demirel University, 32260, Isparta, Turkey \\ ${ }^{2}$ Eğirdir Fruit Research Institute, Eğirdir, Isparta, Turkey
}

Key words: almond, Amygdalus communis L., oil content, fatty acids profile

This study was conducted to determine the total oil contents and fatty acid compositions of some commercial almond cultivars. The total oil contents changed significantly $(\mathrm{p}<0.05)$ by year in all cultivars with the exception of cultivar Ferrastar. Total oil contents were changed from $50.90 \%$ (Picantili) to $62.01 \%$ (Supernova) in 2008 and from 52.44\% (Lauranne) to $63.18 \%$ (Cristomorto) in 2009. While predominant unsaturated fatty acids were oleic and linoleic acids, predominant saturated fatty acid was palmitic acid. The highest amount of oleic acid was obtained in Glorieta in both $2008(83.35 \%)$ and $2009(72.74 \%)$. Linoleic acid content varied by year and the highest content was recorded in Picantili (26.08\%) in 2008 and Yaltinski (30.01\%) in 2009. The highest amount of palmitic acid was detected in cultivar Sonora in both years, i.e. as 7.76\% in 2008 and $10.11 \%$ in 2009. The mean UFA:SFA ratio was 11.73 in 2008 but 7.59 in 2009. Principal component (PC) analysis indicated that palmitic acid, palmitoleic acid, stearic acid, oleic acid, arachidic acid, unsaturated fatty acid (UFA), saturated fatty acid (SFA) and UFA:SFA ratio were primarily responsible for the separation on PC1.

\section{INTRODUCTION}

Almond is among the most cultivated species in the Mediterranean countries as it easily adapts to an arid climate and unfavorable soil conditions, and the demands for the cultivation of almond have been increasing day by day [Akçay \& Tosun, 2005; Beyhan et al., 2011]. Turkey is one of the countries where this increase is the most prominent. In 2013, the increases in production and production area were 33.13 and $32.64 \%$ respectively in the last 3 years. Besides its positive contributions to human health such as reducing obesity, cardiovascular diseases, diabetes, cancer, and the cholesterol level [Socias i Company et al., 2010; Beyhan et al., 2011; Kırbaşlar et al., 2012; Balta, 2013], this increase is caused by its use in many fields such as the cream cake and chocolate industry; the production of dried fruits, confection, and marzipan; ice cream industry; sweetener for beverages; the use of its oil in the pharmaceutical, painting, and cosmetic industries; the use of its green shells as animal feed and the use of its hard shells as fuel and making chipboard [Akçay \& Tosun, 2005; Yildirim et al., 2008].

Stone fruits are known with their biochemical characteristics including high contents of vitamins, phenolic substances and fatty acids. Since recent studies on almond breeding have predominantly focused on late flowering, self-compatibility,

\footnotetext{
* Corresponding Author: Tel.: +90 246211 85 37; Fax: +90 246211 1676

E-mail: adnanyildirim@sdu.edu.tr (Assoc. Prof. Dr. Adnan Nurhan Yildırm)
}

and allele and gene identifications, there is very little information on the biochemical compositions of the cultivars [Moayedi et al., 2011; Kodad \& Socias i Company, 2008]. In the previous studies, it was reported that the genetic characteristic of the cultivar, ecology, physiological factors, cultural practices, the maturity stage of the fruit and harvest time influenced the fatty acid content and composition of the fruit [Rabrenovic et al., 2011; Beyhan et al., 2011; Socias i Company et al., 2010; Zacheo et al., 2000; Habila et al., 2012]. To benefit more efficiently from these fruits, the seeds of which are consumed, more information regarding their storage and the developmental characteristics of the cultivars is required [Femenia et al., 1995]. After a long-storage period and transportation, stone fruits undergo extensive fatty acid oxidation and thus their quality significantly decreases [Kodad \& Socias i Company, 2008; Socias i Company et al., 2010]. Therefore, oil stability and fatty acid composition are important criteria for the evaluation of seed quality [Socias i Company et al., 2010]. Recently, some studies were published about total oil and fatty acid profile of some almond cultivars [Abdallah et al., 1998; Sathe et al., 2008; Özcan et al., 2011; Beyhan et al., 2011]. However, we did not encounter any research on fatty acid profile in some cultivars such as Desmayo Largueta, Ferrastar, Glorieta, Lauranne, Supernova.

In recent studies, it has been suggested that the ratio of oleic acid to linoleic acid could be used as a criterion for determining the almond kernel quality when evaluating oil stability and fatty acid composition [Kodad \& Socias i Com- 
pany, 2008]. Lipid oxidation is particularly associated with factors including the percentage of unsaturated fatty acids, light, oxygen, temperature, and the presence of metallic ions. Besides, lipid oxidation is also influenced by the presence of natural antioxidants like tocopherols which enhance lipid stability [Habila et al., 2012; Socias i Company et al., 2010]. The high rate of unsaturated fatty acids can also extend the shelf life of nuts, and has positive effects on human health [Rabrenovic et al., 2011]. Almond is also rich in unsaturated fatty acids [Abdallah et al., 1998; Sathe et al., 2008].

The main objective of this study was to determine the variation in terms of total oil contents and fatty acid composition of some commercial almond cultivars grown under same ecological conditions. In addition, studied traits were subjected to principal component analysis for the classification and discrimination of almond cultivars. Thus, the nutritional and healthy value as well as the genetic diversity of the studied cultivars will be revealed.

\section{MATERIAL AND METHODS}

\section{Material}

The study was conducted in 2008 and 2009. In the study, the seed samples of 15 almond cultivars (Cristomorto, D. Largueta, Ferraduel, Ferragnes, Ferrastar, Glorieta, Lauranne, Masbovera, Nonpareil, Picantili, Sonora, Supernova, Texas, Tuono, and Yaltinski) grafted on the almond seedling rootstock were used, and the cultivars were obtained from trees in the almond cultivar collection orchard located at Eğirdir Fruit Research Institute in Isparta, Turkey. The study was set up according to a completely randomized design with 3 replications and a tree was used in each replication. When fruits maturated, they were collected from different parts of the trees. The almond fruits were dried for 20 days at room temperature and cracked out by hand. Five hundred grams of almond kernels per cultivar were ground to a powder and placed in plastic bags. Samples were frozen and kept at $-80^{\circ} \mathrm{C}$ until extraction.

\section{Total oil content}

Two $g$ from the ground dry samples were taken and total oil samples were extracted in a Soxhlet apparatus with $100 \mathrm{~mL}$ of petroleum ether as a solvent. The solvent was evaporated under vacuum using a rotary evaporator and the oil was collected [Bligh \& Dyer, 1959]. This process was repeated three times for each almond cultivar.

\section{Fatty acid composition}

Fatty acid methyl esters were prepared using a method described by Marquard [1987]. The fatty acid composition was analyzed by GC 30 (Perkin Elmer Autosystem XL) equipped with a CP-Wax $52 \mathrm{CB}$ column (Varian Inc.) (50 x $0.25 \mathrm{~mm}$, $0.2 \mu \mathrm{m})$. One $\mathrm{mL}$ of Na-ethylate $(0.5 \mathrm{~g} \mathrm{Na}$-methylate + $80 \mathrm{~mL}$ methanol $+20 \mathrm{~mL}$ isooctane) solution was added onto $40 \mu \mathrm{L}$ of oil sample, and esterified. Before injection into $\mathrm{GC}, 0.25 \mathrm{~mL}$ of isooctane was added and the tube was well-shaken. Next, $0.5 \mathrm{~mL}$ was drawn from the upper phase, which became clear, and injected into the GC apparatus by means of a microinjector (Perkin Elmer Autosystem XL). GC condi- tions were: FID detector; injector and detector temperatures: $250^{\circ} \mathrm{C}$; carrier gas was $\mathrm{He}$ at the pressure of $0.069 \mathrm{MPa}$; and flow rate: $30 \mathrm{~mL} / \mathrm{min}$. The oven temperature was held at $80^{\circ} \mathrm{C}$ for $4 \mathrm{~min}$ and then increased to $175^{\circ} \mathrm{C}$. After holding at this temperature for $25 \mathrm{~min}$, the temperature was increased to $215^{\circ} \mathrm{C}$. After holding at $215^{\circ} \mathrm{C}$ for $2 \mathrm{~min}$, the temperature was gradually increased to $240^{\circ} \mathrm{C}$ and then held at this temperature for $10 \mathrm{~min}$. Peaks were identified by their comparison to the relative retention times of standards (Supelco 37 component FAME Mix), and the results were expressed as the percentages of peak areas.

\section{Statistical analyses}

The data were analyzed using SPSS statistical package program and the means were separated with Duncan's Multiple Range test. Principal component analysis was used for the determination of the most significant components. In the principal component analysis, eigenvectors were calculated to determine the contribution of each variable to the separation of the cultivars.

\section{RESULTS AND DISCUSSION}

\section{Total oil}

The total oil contents of the studied cultivars are presented in Table 1. In the study, large differences were found in oil content among the cultivars. The average value of oil content over the 2 years varied from $52.51 \%$ in Picantili to 61.92\% in Cristomorto. The cultivars Cristomorto, Supernova and Ferragnes had a mean value of oil content higher than $60 \%$. The analysis of variance indicated that the effect of the cultivar, year and the interaction cultivar $\mathrm{x}$ year were significant for total oil contents at the level of $p<0.01$. The total oil contents changed significantly $(\mathrm{p}<0.05)$ by year in all cultivars with the exception of cultivar Sonora. The highest total oil content was determined in Supernova (62.01\%) in 2008 , followed by cultivars Ferragnes $(60.92 \%)$ and Cristomorto $(60.66 \%)$. On the other hand, the lowest total oil content was found in Picantili (50.90\%). In 2009, the highest total oil content was recorded in Cristomorto $(63.18 \%)$, followed by cultivars Ferragnes (61.71\%) and Supernova (61.70\%). On the other hand, the lowest total oil content was detected in cultivar Lauranne (52.44\%) (Table 1). These results were in agreement with the results of Kodad et al. [2013], who have reported that the total oil content of almond kernels ranged from $48.7 \%$ to $64.59 \%$. On the other hand, Abdallah et al. [1998] reported that the total oil content of almond kernels changed between $38 \%$ and $53 \%$ DW. Similarly, Kodad et al. [2006] determined slightly higher total oil contents in almond cultivars ranging from $40 \%$ to $65 \%$ DW. In agreement with the results of Kodad et al. [2006], Kodad \&d Socias I Company [2008] reported a total oil content of almond kernels between $48 \%$ to $67 \%$ DW in eight cultivars and 47 advanced self-compatible almond genotypes developed in an almond breeding program. In the previous studies, it was reported that factors including the genetic characteristic of the cultivar, ecology, physiological factors, cultural practices, the maturity stage of the fruit, and harvest time had effects on oil con- 
TABLE 1. Total oil contents of almond kernels (\%).

\begin{tabular}{|c|c|c|c|}
\hline \multirow{2}{*}{ Cultivars } & \multicolumn{2}{|c|}{ Total oil } & \multirow{2}{*}{ Average } \\
\hline & 2008 & 2009 & \\
\hline Cristomorto & $60.66 \pm 0.88^{\mathrm{aB}}$ & $63.18 \pm 0.82^{\mathrm{aA}}$ & 61.92 \\
\hline D. Largueta & $54.90 \pm 2.10^{\text {defB }}$ & $59.80 \pm 1.69^{\mathrm{bcdA}}$ & 57.35 \\
\hline Ferraduel & $55.54 \pm 1.42^{\mathrm{cdeB}}$ & $60.82 \pm 1.32^{\mathrm{bcA}}$ & 58.18 \\
\hline Ferragnes & $60.92 \pm 1.20^{\mathrm{aB}}$ & $61.71 \pm 1.04^{\mathrm{abA}}$ & 61.32 \\
\hline Ferrastar & $57.40 \pm 1.69^{\mathrm{bcB}}$ & $57.95 \pm 1.57^{\text {defA }}$ & 57.68 \\
\hline Glorieta & $53.59 \pm 1.73^{\mathrm{efB}}$ & $54.52 \pm 1.84^{\mathrm{hA}}$ & 54.06 \\
\hline Lauranne & $56.30 \pm 0.84^{\text {bcdA }}$ & $52.44 \pm 0.93^{\text {В }}$ & 54.37 \\
\hline Masbovera & $53.39 \pm 1.57^{\mathrm{fB}}$ & $55.19 \pm 1.63^{\mathrm{ghA}}$ & 54.29 \\
\hline Nonpareil & $55.99 \pm 1.13^{\mathrm{bcdB}}$ & $57.56 \pm 1.26^{\mathrm{gfA}}$ & 56.78 \\
\hline Picantili & $50.90 \pm 1.79^{\mathrm{gB}}$ & $54.12 \pm 1.28^{\mathrm{hiA}}$ & 52.51 \\
\hline Sonora & $58.03 \pm 2.17^{\mathrm{aB}}$ & $55.48 \pm 1.03^{\mathrm{ghB}}$ & 56.76 \\
\hline Supernova & $62.01 \pm 0.96^{\mathrm{aA}}$ & $61.70 \pm 1.12^{\mathrm{abB}}$ & 61.86 \\
\hline Texas & $52.95 \pm 1.74^{\mathrm{IB}}$ & $58.95 \pm 1.37^{\mathrm{cde} A}$ & 55.95 \\
\hline Tuono & $57.79 \pm 1.40^{\text {ьв }}$ & $56.89 \pm 1.02^{\mathrm{fgA}}$ & 57.34 \\
\hline Yaltinski & $56.51 \pm 0.33^{\mathrm{bcdB}}$ & $60.82 \pm 0.73^{\mathrm{bcA}}$ & 58.67 \\
\hline Average (year) & 56.46 & 58.07 & \\
\hline LSD & & 1.907 & \\
\hline
\end{tabular}

Each value is expressed as mean \pm standard deviation. Means followed by different capital letters (years) in the row are significantly different $(\mathrm{p}<0.05)$. Means followed by different small letters in the columns (cultivars) are significantly different $(\mathrm{p}<0.05)$.

tents [Sathe et al., 2008; Rabrenovic et al., 2011; Beyhan et al., 2011; Socias i Company et al., 2010; Zacheo et al., 2000; Habila et al., 2012].

\section{Fatty acids}

The fatty acid compositions of the studied cultivars are shown in Table 2. It was also found the large variability for fatty acids. The analysis of variance showed that the effect of the cultivar, year and the interaction cultivar x year were significant for all fatty acids except heptadecanoic acid $(p<0.05)$. The highest content of oleic acid was obtained in Glorieta in both 2008 (83.35\%) and 2009 (72.74\%). On the other hand, the lowest content of oleic acid was detected in Picantili (62.89\%) in 2008 and in Yaltinski (55.14\%) in 2009 (Table 2). Kodad et al. [2013] reported oleic acid contents ranging from $61.8 \%$ to $80.2 \%$ of total oil in kernels of selected almond genotypes. In turn, Sathe et al. [2008] determined oleic acid contents varying from $57.54 \%$ to $73.94 \%$ of total oil in eight almond cultivars from 12 different California counties. Moreover, Moayedi et al. [2011] showed that the main monounsaturated fatty acid was oleic acid with the content ranging from $66.7 \%$ to $69.7 \%$ of total oil in the kernels of three wild almond species. In agreement with our results, Kurbaşlar et al. [2012] reported $71.98 \%$ oleic acid content in an almond genotype in Turkey. However, as compared to our re- sults, the lower amounts of oleic acid ranging from $72.5 \%$ to 79.97\% have been reported by Özcan et al. [2011] in different commercial almond cultivars. This may be due to different cultural and ecological conditions in studies. Moreover, high temperature has a negative effect on the syntheses of linoleic and linolenic acids in plants but has a positive effect on the synthesis of oleic acid [Beyhan et al., 2011]. In the study, linoleic acid content also varied by year and the highest value was recorded in Picantili (26.08\%) in 2008 and Yaltinski $(30.01 \%)$ in 2009 but the lowest value was obtained from Masbovera (9.27\%) in 2008 and Tuono (9.82\%) in 2009. The highest value of palmitic acid was detected in cultivar Sonora in both years, i.e. as $7.76 \%$ in 2008 and $10.11 \%$ in 2009 . On the other hand, the lowest content of palmitic acid was recorded in cultivar Texas $(4.34 \%)$ in 2008 and in cultivar Nonpareil $(6.63 \%)$ in 2009 . The amounts of palmitoleic acid were much higher in 2009, and the highest value was detected in cultivar Ferraduel (0.67\%) in 2008 and in cultivar Nonpareil $(0.73 \%)$ in 2009 . The lowest content of palmitoleic acid in both years was obtained from cultivar Texas, i.e. as $0.21 \%$ in 2008 and $0.22 \%$ in 2009 . In the study, the highest amount of stearic acid was found in cultivar Ferrastar $(3.58 \%)$ but the lowest one in cultivar Cristomorto $(0.77 \%)$ in 2008 . On the other hand, in 2009 the highest content was detected in cultivar Picantili $(4.71 \%)$ but the lowest one in cultivar Nonpareil (1.71\%). Arachidic acid was determined in trace amounts in 2008. In 2009, the highest amount was obtained in the cultivars Desmayo Largueta and Sonora (0.07\%) but the lowest amount in the cultivars Nonpareil and Supernova $(0.02 \%)$ (Table 2). Similar results have been reported in previous studies [Abdallah et al., 1998; Sathe et al., 2008; Beyhan et al., 2011; Moayedi et al., 2011; Gupta et al., 2012; Kırbaşlar et al., 2012; Balta, 2013]. Fruit genotype, ecology, harvest time and maturity have effects on the fatty acid composition of plants [Beyhan et al., 2011; Habila et al., 2012; Sathe et al., 2008].

Nutrients with a high rate of unsaturated fatty acid have been preferred in human nourishment in the recent years [Özcan et al., 2011]. Monounsaturated fatty acids (MUFAs) (oleic acid, palmitoleic acid, and heptadecanoic acid) and polyunsaturated fatty acids (PUFAs) (linoleic acid and linolenic acid) are found at high rates in the seeds of stone fruits including almond and constitute the majority of the total oil. MUFAs have been reported to be as effective in reducing the cholesterol level in human beings as PUFAs [Kodad \& Socias I Company, 2008; Kırbaşlar et al., 2012]. Especially oleic acid ( $\omega-9$ family) is reported to remarkably reduce the effect of the gene causing breast cancer [Kırbaşlar et al., 2012]. In addition, linoleic acid was shown to be effective in the repair of DNA damage, in the regulation and development of cell differentiation, in providing immunological activation, and in the regulation of blood pressure and blood coagulation in human beings [Beyhan et al., 2011; Kırbaşlar et al., 2012]. Unsaturated fatty acids also significantly extend the shelf life of nuts if they are stored under favorable conditions [Sathe et al., 2008]. Moreover, MUFAs have been reported to increase oxidative stability in oils [Habila et al., 2012; Kırbaşlar et al., 2012]. Unsaturated fatty acids are affected by environmental factors like light, temperature, 


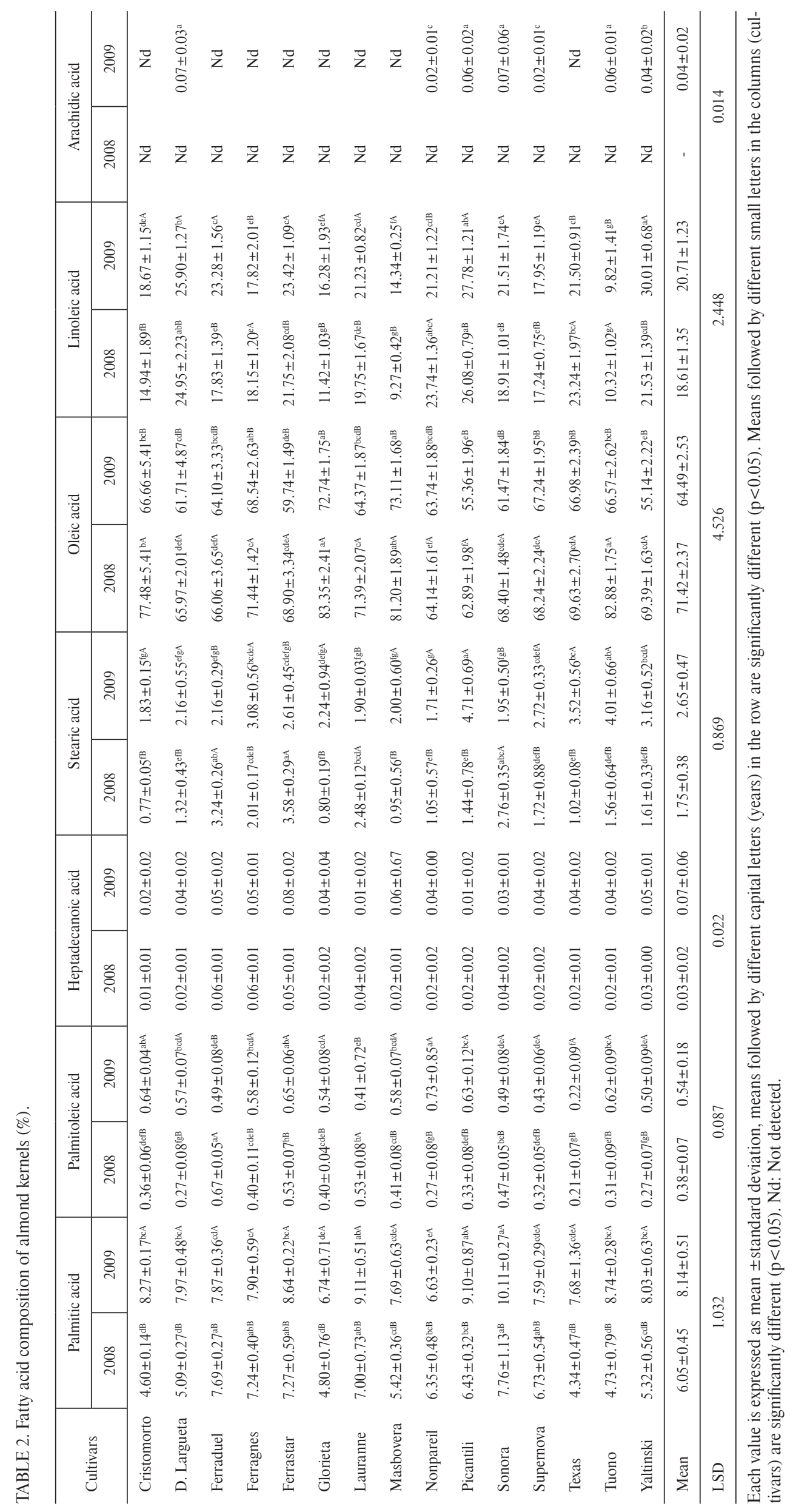


TABLE 3. The rates of UFA, SFA and UFA:SFA in almond kernels.

\begin{tabular}{|c|c|c|c|c|c|c|c|c|c|}
\hline \multirow{2}{*}{ Cultivars } & \multicolumn{3}{|c|}{ UFA $(\%)$} & \multicolumn{3}{|c|}{ SFA $(\%)$} & \multicolumn{3}{|c|}{ UFA:SFA } \\
\hline & 2008 & 2009 & Mean & 2008 & 2009 & Mean & 2008 & 2009 & Mean \\
\hline Cristomorto & 92.43 & 85.35 & 88.89 & 5.73 & 10.74 & 8.24 & 16.13 & 7.94 & 12.04 \\
\hline D. Largueta & 90.94 & 87.65 & 89.30 & 6.68 & 10.77 & 8.73 & 13.61 & 8.13 & 10.87 \\
\hline Ferraduel & 83.95 & 81.98 & 82.97 & 11.6 & 10.52 & 11.06 & 7.23 & 7.79 & 7.51 \\
\hline Ferragnes & 89.65 & 86.41 & 88.03 & 9.65 & 11.56 & 10.61 & 9.29 & 7.47 & 8.38 \\
\hline Ferrastar & 90.70 & 83.24 & 86.97 & 11.35 & 11.90 & 11.63 & 7.99 & 6.99 & 7.49 \\
\hline Glorieta & 94.79 & 89.06 & 91.93 & 6.00 & 9.52 & 7.76 & 15.79 & 9.35 & 12.57 \\
\hline Lauranne & 91.18 & 85.61 & 88.40 & 10.01 & 11.42 & 10.72 & 9.11 & 7.49 & 8.30 \\
\hline Masbovera & 90.49 & 87.51 & 89.00 & 6.78 & 10.27 & 8.53 & 13.35 & 8.52 & 10.94 \\
\hline Nonpareil & 87.95 & 84.99 & 86.47 & 7.67 & 9.09 & 8.38 & 11.47 & 9.35 & 10.41 \\
\hline Picantili & 88.99 & 83.15 & 86.07 & 8.20 & 14.50 & 11.35 & 10.85 & 5.73 & 8.29 \\
\hline Sonora & 87.35 & 83.01 & 85.18 & 10.99 & 12.62 & 11.81 & 7.95 & 6.58 & 7.27 \\
\hline Supernova & 85.50 & 85.23 & 85.37 & 8.77 & 10.76 & 9.77 & 9.75 & 7.92 & 8.84 \\
\hline Texas & 92.89 & 88.52 & 90.71 & 5.57 & 11.42 & 8.50 & 16.68 & 7.75 & 12.22 \\
\hline Tuono & 93.22 & 76.43 & 84.83 & 6.60 & 13.43 & 10.02 & 14.12 & 5.69 & 9.91 \\
\hline Yaltinski & 90.95 & 85.20 & 88.08 & 7.20 & 11.73 & 9.47 & 12.63 & 7.26 & 9.95 \\
\hline Mean & 90.07 & 84.89 & 87.48 & 8.19 & 11.35 & 9.77 & 11.73 & 7.59 & 9.66 \\
\hline
\end{tabular}

TABLE 4. Principal component analysis in almond kernels.

\begin{tabular}{l|ccc}
\hline \multirow{2}{*}{ Variables } & \multicolumn{3}{|c}{ Principal component } \\
\cline { 2 - 4 } & 1 & 2 & 3 \\
\hline Total fatty acid (\%) & 0.216 & 0.167 & 0.805 \\
Palmitic acid (\%) & 0.914 & 0.033 & 0.058 \\
Palmitoleic acid (\%) & 0.607 & 0.329 & 0.268 \\
Heptadecanoic acid (\%) & 0.337 & 0.503 & -0.552 \\
Stearic acid (\%) & 0.777 & 0.156 & -0.130 \\
Oleic acid (\%) & -0.756 & 0.586 & 0.055 \\
Linoleic acid (\%) & 0.362 & -0.866 & -0.027 \\
Arachidic acid (\%) & 0.597 & -0.059 & -0.209 \\
UFA & -0.770 & -0.076 & 0.040 \\
SFA & 0.961 & 0.109 & -0.004 \\
UFA:SFA & -0.943 & -0.076 & -0.113 \\
\hline Eigenvalue & 5.430 & 1.535 & 1.107 \\
\hline Percent variation & 49.36 & 13.95 & 10.07 \\
\hline Cumulative percent variation & 49.36 & 63.32 & 73.38 \\
\hline
\end{tabular}

and oxygen and are being oxidized, an event called rancidification [Bingöl, 1976]. The fatty acids which have undergone rancidification contain peroxide-type molecules. These molecules have a destructive effect on vitamins [Bingöl, 1976]. In the study, it was determined that almond cultivars were rich in unsaturated fatty acids. The highest rates of unsaturated fatty acids among the cultivars were obtained in cultivar Glorieta in both years (Table 3). The rates of unsaturated fatty acids ranged from $83.95 \%$ (Ferraduel) to $94.79 \%$ (Glorieta) in 2008 and from $76.43 \%$ (Tuono) to $89.06 \%$ (Glorieta) in 2009. On the other hand, the saturated fatty acids (SFAs) contents were determined to vary from $5.73 \%$ (Cristomorto) to $11.35 \%$ (Ferrastar) in 2008 and from $9.09 \%$ (Nonpareil) to $14.50 \%$ (Picantili) in 2009 (Table 3). These results were found higher than those in the previous studies [Balta, 2013; Yildirim et al., 2008]. The mean UFA/SFA ratio was 11.73 in 2008 but 7.59 in 2009 (Table 3). Considering the average of 2 years data, the cultivars Glorieata, Texas and Cristomorto had a higher value than the others for UFA:SFA ratio.
The almond kernel has a tendency to molding during storage and transportation due to the oxidation of the fatty acids it contains, which causes loss of quality. Therefore, the ratio of oleic acid to linoleic acid (O:L) is considered a significant quality criterion for the evaluation of almond kernel quality and the high O:L ratio in particular is considered as an important factor providing stability in oils as well as a higher nutritional value [Kodad et al., 2011, 2013]. According to data, the cultivars Tuono, Masbovera and Glorieta showed high and stable contents of oleic acid and low contents of linoleic acid and also high O:L values during the 2 years studied.

PCA is a multivariate statistical method that causes data reconstruction and reduction. Therefore, PCA was used for the discrimination of almond. The characteristics with the eigenvalues greater than 1 are evaluated to be descriptive in PCA [Shin et al., 2010]. Results from the principal component analysis presented in Table 4 indicate that the first 3 components explained $73.38 \%$ of the total variability observed. PC1, PC2 and PC3 components accounted for 49.36\%, 13.95\% and $10.07 \%$ of the total variance, respectively. PC1 showed 8 variables with higher scores (values $\geq 0.50$ ) related to fatty acid component (palmitic acid, palmitoleic acid, stearic acid, oleic acid and arachidic acid) and fatty acid ratio (UFA, SFA and UFA:SFA). The highest contribution of PC2 corresponded to linoleic acid, oleic acid and heptadecanoic acid. The separation along PC3 was primarily due to variations in total fatty acid and heptadecanoic acid. These results support the relevance of SFA, UFA:SFA, palmitic acid, linoleic acid and total fatty acid as discriminant parameters that differentiate almond cultivars. Similar results were reported in previous PCA applications to almond research [Carratala et al., 1998; Shin et al., 2010; Colic et al., 2012; Kodad et al., 2013].

\section{CONCLUSIONS}

Cristomorto, Supernova and Ferragnes appeared to be predominant cultivars in terms of total oil content based on average data of 2 years. Glorieta and Texas cultivars 
were noticeable in terms of unsaturated fatty acids $(91.93 \%$, $90.71 \%$, respectively). In addition, the total oil contents of Tuono, Masbovera, Glorieta and Cristomorto cultivars were similar in both years. The highest ratio of UFA:SFA was obtained from Glorieta, Texas and Cristomorto cultivars. It was concluded that the commercial value of these cultivars would be increased and they could be used as parents in breeding studies. Moreover, Cristomorto was the most important cultivar with regard to high total oil, unsaturated fatty acid and oil stability characteristics.

\section{ACKNOWLEDGEMENTS}

This research was supported by Suleyman Demirel University and Eğirdir Fruit Research Station, Isparta, Turkey. We also thank to Dr. Yaşar Karakurt for proofreading the manuscript.

\section{REFERENCES}

1. Abdallah A., Ahumada M.H., Gradziel T.M., Oil content and fatty acid composition of almond kernels from different genotypes and California production regions. J. Am. Soc. Hort. Sci., 1998, 123, 1029-1033.

2. Akçay M.E., Tosun İ., Determination of some late flowering foreign almond cultivars attitute of growing and yield in Yalova region. J. Fac. Agric., 2005, 36, 1, 1-5.

3. Balta M.F., Fatty acid profiles for almond [Prunus amydalus Batsch] genotypes with different kernel taste and formation. Iğdır Univ. J. Inst. Sci. Tech., 2013, 3, 1, 17-24.

4. Beyhan Ö., Aktaş M., Yılmaz N., Şimşek N., Gerçekçioğlu R., Determination of fatty acid composition of some important almond [Prunus amydalus L.] varieties selected from Tokat province and Eagean region of Turkey. J. Medic. Plants Res., 2011, 5 , 4907-4911.

5. Bingöl G., Lipids. Ankara University Faculty of Pharmacy Publications. Pub. No:41, 1976, Ankara, Turkey, p. 68.

6. Bligh E.G., Dyer, W.J., A rapid method of total lipid extraction and purification. Can. J. Biochem. Physiol., 1959, 37, 911-917.

7. Carratala M.L.M., Garcia-Lopez C., Berenguer-Navarro V., Grane-Teruel N., New contribution to the chemometric characterization of almond cultivars on the basis of their fatty acid profiles. J. Agric. Food Chem., 1998, 46, 963-967.

8. Colic S., Rakonjac V., Zec G., Nikolic D., Aksic M.F., Morphological and biochemical evaluation of selected almond[Prunus dulcis (Mill.) D.A. Webb] genotypes in northern Serbia. Turk. J. Agric. Forestry, 2012, 36, 429-438.

9. Femenia A., Rosello C., Mulet A., Canellas J., Chemical composition of bitter and sweet apricot kernel. J. Agric. Food Chem. 1995, 43, 356-361.

10. Gupta A., Sharma P.C., Tilakratne B.M.K.S., Verma A.K., Studies on physico-chemical characteristics and fatty acid composition of wild apricot [Prunus armeniaca Linn.] kernel oil. Ind. J.Nat. Prod. Res., 2012, 3, 366-370.

11. Habila N., Inuva H.M., Aimola I.A., Agbaji A.S., Ladan Z., Shangodare R., Williams I.S., Odjobo O.B., Ogabiela E., Varia- tion of fatty acids and vitamin E composition in seed oils of some plant species. J. Plant Stud., 2012, 1, 2, 55-60.

12. Kırbaşlar F.G., Türker G., Özsoy-Güneş Z., Ünal M., Dülger B., Ertaş E., Kızılkaya B., Evaluation of fatty acid composition, antioxidant and antimicrobial activity, mineral composition and calorie values of some nuts and seeds from Turkey. Rec. Nat. Prod., 2012, 6, 339-349.

13. Kodad O., Socias i Company R., Prats M.S., López Ortiz M.C., Variability in tocopherol concentrations in almond oil and its use as a selection criterion in almond breeding. J. Hort. Sci. Biotechnol., 2006, 81, 501-507.

14. Kodad, O., Estopanan G., Juan T., Socias I Company R., Protein content and oil composition of almond from Moroccan seedlings: Genetic diversity, oil quality and geographical origin. J. Am. Oil Chem. Soc., 2013, 90, 243-252.

15. Kodad, O., Socias I Company R., Variability of oil content and of major fatty acid composition in almond [Prunus amydalus Batsch] and its relationship with kernel quality. J. Agric. Food Chem., 2008, 56, 4096-4101.

16. Kodad, O., Alonso, J.M., Espiau, M.T., Estopanan, G., Juan, T., Socias i Company, R., Chemometric characterization of almond germplasm: compositional aspects involved in quality and breeding. J. Amer. Soc. Hort. Sci., 2011, 136, 273-281.

17. Marquard R., Qualitatsanalytic im dienste der ölfflanzenzüctung. Fat Sci. Technol., 1987, 89, 95-99 (in German).

18. Moayedi A., Rezeai K., Moini S., Keshavarz B., Chemical compositions of oils from several wild almond species. J. Am. Oil Chem. Soc., 2011, 88, 503-508.

19. Özcan M.M., Ünver A., Erkan E., Arslan D., Characteristics of some almond kernel and oils. Sci. Hortic., 2011, 127, 330-333.

20. Rabrenovic B., Dimic E., Maksimovic M., Sobajic S., Gajic-Krstajic L., Determination of fatty acid and tocopherol compositions and the oxidative stability of walnut [Juglans regia L.] cultivars grown in Serbia. Czech J. Food Sci., 2011, 29, 74-78.

21. Sathe S.K., Seeram N.P., Kshırsagar H.H., Heber D., Lapsley K.A., Fatty acid composition of California grown almonds. Food Chem., 2008, 73, C607-C614.

22. Shin E.C., Craft B.D., Pegg R.B., Phillips R.D., Eitenmiller R.R., Chemometric approach to fatty acid profiles in Runner-type peanut cultivars by principal component analysis (PCA). Food Chem., 2010, 119, 1262-1270.

23. Socias i Company R., Kodad O., Alonso J.M., Font-Forcada C., Fruit quality in almond: Chemical aspects for breeding strategies. XIV GREMPA Meeting on Pistachios and Almonds, 2010, 94, 235-243.

24. Yildirim A.N., Koyuncu F., Tekintas E., Yildirim F.A., Fatty acid content and some chemical properties of selected almond [Prunus amygdalus Batsch] genotypes in Isparta province. J. Adnan Menderes Univ. Agric. Fac., 2008, 5, 1, 19-25.

25. Zacheo G., Cappello M.S., Gallo A., Santino A., Cappello A.R., Changes associated with postharvest ageing in almond seeds. LWT - Food Sci. Tech., 2000, 33, 415-423.

Submitted: 19 November 2014. Revised: 5 January and 27 February 2015. Accepted: 16 March 2015. Published on-line: 11 March 2016. 